\title{
O Direito Internacional Privado do Novo Milênio: A Proteção da Pessoa Humana Face à Globalização ${ }^{1}$
}

\section{Prof. Dr. Dr. h.c. mult Erik Jayme}

\section{INTRODUÇÃO}

\section{A globalização: possibilidades e problemas para a pessoa humana ${ }^{2}$}

A globalização do mundo ${ }^{3}$, e sobretudo o comércio internacional, suscitou, recentemente, preocupaçôes profundas, que se tornaram expressas e manifestas quando das reuniões da Conferência das Nações Unidas sobre o comércio e o desenvolvimento, organizadas em Seatle (1999) e em Bangkok (2000). Estas conferências foram acompanhadas de protestos e demonstrações de rua, algumas vezes violentas, dos chamados adversátios de um comércio sem fronteiras. Temese que a globalização viole a dignidade da pessoa humana, particularmente dos povos ainda menos desenvolvidos. É a identidade cultural do indivíduo que se sente ameaçada pela mundialização do comércio e que se opõe a esta.

Assim também, a passagem para o novo milênio parece ter sido marcada mais pelos problemas e dúvidas do que pelas possibilidades e esperanças. ${ }^{4} \mathrm{Na}$ França, o "processo

3 Conferência Magna de Abertura do Curso da Academia de Direito Internacional de Haia de 2000, pronunciada em 21 de julho de 2000, no Palácio da Paz, Haia, e publicada no Recueil des Couts de P'Académie de Droit International de la Haye, tomo $282(2000)$, p. 9 a 40. Tradução livre do francês, autorizada pelo autor, e realizada pela Profa. Dra. Claudia Lima Marques, UFRGS (primeira parte e notas) e Profa. Dra. Nádia de Araujo, PUC-/Rio (segunda parte e conclusão).

2 N. da T. - Nesta tradução deu-se preferência a manter o jogo de palavas e o aspecto retórico-poético do texto original ("chances et craintes de la personne humaine"), do que o sentido literal.

3 Para uma definição de globalização, veja Jost Delbrück, "Globalization of Law, Poiltics, and Markets- Implications for Domestic Law-A European Perspective", Incliana Joumal of Global Srudies, 1(1993), pp. 9 ss., pp. 10-11. Veja também Eric Loquin e Catherine Kessedjian (dir. publ.), La mondialisation du droit, Dijon, 2000.

"Veja Hans-Peter Martin e Harald Schumann, Die Globalisierungsfalle- Der Angriff auf Demokratie und Wollstand, Hamburgo, 1998. 
Bové", que se refere ao ataque a um restaurante MacDonald, resultou em uma "festa antiglobalização", à qual o jornal Le monde dedicou quatro páginas centrais. ${ }^{5}$

Efetivamente, nós assistimos a fenômenos contraditórios: de um lado, qualquer um pode fácilmente se libertar das marras de sua existência limitada: velocidade, ubiqüidade, liberdade; o espaço, para a comunicação, não existe mais. ${ }^{6}$ Hoje os eventos de alegria e tristeza unem os seres humanos em um sentimento global de solidariedade que era desconhecido das gerações anteriores. De outro lado, cada catástrofe, apesar de parecer bastante distante da esfera dos negócios de cada um, acaba, em realidade, a repercutir na vida privada de cada um. Experimentamos um sentimento de perda da segurança de uma existência protegida pelas instituições tradicionais, como o Estado e os juízes estatais.

Em verdade, a globalização é caracterizada pelo fato dos Estados não serem maís os centros do poder e da proteção da pessoa humana. ${ }^{7}$ Os Estados estão cedendo grande parre de seus poderes aos mercados. As regras da concorrência determinam a vida e o comportamento dos seres humanos. ${ }^{8}$ A existência de um mercado global permite fusões de grandes empresas, resultando em un poder econômico gigantesco, que deixa aberta a questão da proteção do indivíduo que gostaria de manter seu posto de trabalho, ${ }^{g}$ proteção tradicionalmente fornecida pelo Estado. Para preencher este vazio legal, os juristas reclamam a criação de um sistema mundial de proteção contra as práticas anti-concorrênciais. ${ }^{10}$

Quando o Estado falta, são as organizaçōes não-governamentais, seguidamente, que, em muitos campos, tomam a si os interesses de proteção, sobretudo, dos interesses globais, ${ }^{11}$ mesmo se as Nações Unidas também se ocupam do tema. ${ }^{12}$ Se nós pensamos a proteção do meio ambiente, a globalização modificou nossa consciência: existe um interesse global, por exemplo, de manter o clima da Terra ou de proteger a qualidade da água, interesses que importam à vida dos indivíduos.

"Le Monde, data de 30 de junho de 2000, pp. 1, l-rV.

"St. Hobe, "Die Zukunft des Völkerrechts im Zeitalter der Globalisierung", Archiv des Völketrechts, 37 (1999), pp. 253 ss., p. 254.

7 Veja K. Dicke, W. Hummer, D. Girsberger, K. Boele-Woelki, Ch. Engel, j. Frowein, "Völkerrecht und Internationales Privatrecht in einem sich globalisierenden internationalen Syztem- Auswirkungen der Entstaatlichung transnationaler Rechstbeziehungen", Bericht der Deutschen Gesselchaft für Völkerrecht, vol. 39, Heidelberg, 2000.

\& Veja S. Strange, The Retraet of the State: The diffusion of Power in the World Economy, Cambridge, 1996.

"Veja C. di Turi, "Globalizzazione dell'economia e diritti fondamentali in materia di lavoro", Rivista di diritto internazionale, $2000, \mathrm{pp} .13$ ss.

${ }^{10}$ Veja Jürgen Basedow, Weltkartelrecht, Ausgange und Ziele, Methoden und Grenzen der internationalen Vereinheitlichung des Rechts der Wettbewerbsbeschränkungen, Tübingen, 1998; Kathleen Luz, "NoteThe Boeing/Macdonnel Merger: Competition Law, Parrocchialism, and the Need for a Globazed Anritrust System", The George Washington Journal of International Law and Economics, 32 (1999), pp. 155 ss.

1 De tais organizações surgiram os temas estudados recentemente, veja, por exemplo, Stephan Hove, "Der Rechtsstatus der Nichtregierungsorganisationen nach gegenwärtigem Völkerrecht", Archiv für Völkerrecht, 37 (1999), pp, 152

12 Veja Jost Delbrück, "The Role of the Unitect Nations in daling with global problems", Indiana Journal of Global Legal Studies, 4 (1997), pp. 277ss. 
No que concerne às novas tecnologias, a comunicação, facilitada pelas redes globais, determina uma maior vulnerabilidade daqueles que se comunicam. Cada um de nós, ao utilizar pacificamente seu computador, já recebeu o choque de perceber que uma força desconhecida e exterior invadia o seu próprio programa, e o fato de não conhecer seu adversátio preocupa ainda mais. Os juristas combatem as práticas fraudulentas através dos instrumentos clássicos da responsabilidade civil delitual, enquanto os malfeitores escapam a todos os controles e se protegem em um espaço virtual. De outro lado, o comércio eletrônico levanta a questão do sistema jurídico de proteção efetiva dos consumidores. ${ }^{13}$

Observe-se, agora, o direito internacional privado, destinado a tornat-se uma das matérias-chave para a proteção da pessoa humana, sendo este objetjvo considerado a razão mesmo de ser do direito privado, ainda mais uma vez que as soluções dos conflitos de leis pressupõem um diálogo intercultural, a respeitar a diversidade dos indivíduos. Nós devemos, pois, nos perguntar qual é e qual deveria ser a reação do direito internacional privado face à globalização, sobretudo no que concerne a proteção do indivíduo.

Para este fim, eu me permito relembrar as três características de nosso tempo: 'velocidade, ubigüidade, liberdade', de acordo com o manifesto futurista de Tomaso Marinetti enunciado no início do século $X X{ }^{14}$ Nós assistimos ao fato da velocidade mesmo se tornar um valor jurídico, com impacto visivel no direito internacional privado, qual seja o interesse do legislador e do juiz concentrado nas medidas provisórias rápidas. ${ }^{15}$ De outro lado, a velocidade e a ubiqüidade caracterizam os procedimentos relativos à execução de sentenças estrangeiras destinadas a facilitar a "livre circulação de decisões". A pessoa humana, que reage menos rapidamente, parece ficar sem proteção.

A primeira parte desta conferência será, por conseguinte, consagrada a uma crítica das tendências aruais. Na segunda parte, procurarei desenvolver um sistema de proteção baseada na autonomia da vontade dos individuos e sobre as idéias de proteção da identidade cultural da pessoa humana.

\section{I - Crítica às tendências atuais do Direito Internacional Privado}

\section{A velocidade: o Divórcio na Europa}

A tendência atual na Europa coloca o direito internacional privado a serviço da integração, de forma a criar um espaço único de direito. ${ }^{16}$ A convenção sobre a competência,

${ }_{1.3}$ Veja F. Vischer, L. Huber, D. Oser, Intennationales Vertragsrecht, 2.ed., Berna, 2000, p. 342.

14 Veja E. Jayme, "Zum Jahrtausendwechsel: Das Kollisionsrecht zwischen Postmoderne und Futurismus", IPRAX 2000, pp. 165 ss.

is Veja O. Hartwieg e J.Grunert, "Bedarf und Möglichkeiten provisorischer Eilverfügungen im ECommerce", ZIP-Zeitschrift für Wirtschaftsrecht, 2000, pp. 721 ss, 727: "Jeder der ztvor skizzierten Versuche muss sich an seiner 'Schnelligkeit' messe lassen."

16 Veja Ch. Kohler, "Interrogations sur les sources du droit internationale privé européen après le traité d'Amsterdan", Rev. crit.dr.int.pr., 1999,pp. 1ss. 
o reconhecimento e a execução das decisões em matéria matrimonial de $1998^{17}$, que está em vias de ser transformada em Regulamento comunitário europeu ${ }^{18}$, é o exemplo mais marcante desta tendência.

A idéia base desta convenção é a seguinte: a livre circulação das pessoas- uma das quatro liberdades fundamentais do direito comunitírio europeu- será assegurada de forma mais eficaz se uma pessoa, que se transfere do território de um Estado para outro Estado membro da União Européia, pode manter consigo sua situação familiar. Partindo desta idéia é que se facilita a circulação de sentenças de divórcio. As decisões, que rejeitam um pedido de divórcio, ao contrário, não se beneficiam de inclusão na referida Convenção ${ }^{19}$. Ainda, a incompetência do juízo não se encontra entre os motivos de não-reconhecimento da sentença estrangeira. Da mesma forma, as disparidades (ou falhas) da lei aplicada também não. Assin, dispõe $\mathrm{o}$ art. $17 \mathrm{da}$ Convenção:

"Oreconbecimento de uma decisãoem matéria de divórcio, de separaçĩo de conpos onde anulasão docasamento näopode ser recusada pelo fato da leido Estado membro de reconbecimentonão permitito divórcio, a separação de corpos ow a anulaşão do casamento em casos idênticos ${ }^{20}$

A Convenção fixa também a competência dos juízes. Dentre os elementos-chave aparece a "residência habitual do autor se ele reside pelo menos há um ano imediatamente antes da ação." (Art. 2, parágrafo 1, letra 'a').

Estas regras novas não são compatíveis com os princípios do direito internacional clássico. Elas favorizam o esposo que deseja o divórcio. A visão do cônjuge que continua em seu país de origem e deseja manter seu casamento não interessa mais ao legislador europeu. Se o cônjuge emigra para um país e lá resida por um ano, ele pode regular seus 'negócios' de família conforme deseje. Uma certa restrição existe, quanto ao cônjuge que retorna ao seu país de origem. Ele deve esperar. seis meses até poder entrar com a ação de divórcio, enquanto o outro cônjuge, que fica no país do último domicílio conjugal pode requerer o divórcio imediatamente. De um outro lado, o cônjuge que fica, praticamente, fica obrigado a agir nestes seis meses, para evitar a ação do outro. Assim, a Convenção favoriza ela a velocidade, assim como uma verdadeira "ubiqüidade" do divórcio.

É igualmente significativo o fato anteriormente que as falhas na aplicação (disparités) da lei indicada aplicada não devem ser mais um obstáculo ao reconhecimento do divórcio ${ }^{21}$.

17 "Convention établie sur la base de l'article K.3 du Traité sur l’Union européenne, concernant la compétence, la reconnaissance et l'execution des décisions en marière matrimoniale", JOCE, n. L221, de 16 de juho de 1998, p. 2, Rev, crit.drint.pr., 1998, pp. 776 ss.

18 Veja Regulamento (CE) n. $1347 / 2000$ do Conselho de 29 de maio de 2000 , JOCE n. L 160, de 30 de junho de 2000, Pp. 19s. O regulamento entratá em vigor em primeiro de março de 2001.

"Veja W. Hau, "Internarionales Eheverfahrensrecht in der Europäischen Union", FamRZ, 1999, pp. 484 ss., p. 487.

${ }^{20}$ No original citado em francês: "La reconnaissance d’une décision rendue en matière de divorce, de séparation de corps ou d'annulation du mariage ne peut être refuse que la loi de l'Etat membre requis ne permettrai pas le divorce, la séparation de corps ou lannulation du marriage sur la base de faits identiques."

2 Veja art. 27, n. 4 da Convenção de Bruxelas (21 de setembro de 1968). 
Isto como que convida à prática do forum shopping; o cônjuge mais rápido juridicamente, ganha a batalha...

Assim, pensa-se na elaboração de regras uniformes de direito internacional privado em matéria de divórcio, tais regras ficaram já esvaziadas de conteúdo, pois que sem influência decisiva sobre o reconhecimento de sentenças.

A finalidade clássica do Direito internacional privado era a de garantir a igualdade entre as pessoas e entre sistemas jurídicos e salvaguardar a harmonia de decisões através da escolha de um elemento de conexão comum mais próximo da família. Em nossos dias, o efcito integrativo da livte circulação de pessoas é mais importante que os valores da estabilidade e da continuidade das famílias. O estado das pessoas é tratado, por estas regras comunitárias, como uma mercadoria...

Certamente, podemos retornar aos valores anteriores, porém, a questão que se põe é de saber qual a solução mais apropriada para salvaguardar a pessoa humana, questão esta que procurarei responder na segunda parte desta conferência.

\section{A ubiqüidade: a localização do comércio eletrônico e os conflitos de leis e de jurisdição.}

\section{a) A localização dos negócios relativos à Internet}

Em se tratando do comércio eletrônico e dos litígios relativos aos negócios comerciais que tem como base a Internet, a ubiqüidade deste meio de comunicação enseja muitas questões jurídicas, particularmente em matéria de confliros de leis e de conflitos de jurisdição, onde pressupõem-se conexôes territoriais. ${ }^{22}$

Em matéria de contratos concluidos pela Internet, a questão que se coloca é a de saber se as empresas que oferecem seus serviços por Internet, assim como os provedores, podem ser atraídos para o tribunal de domićlio de cada um dos usuários. As regras de competência judiciária, tais quais as conhecemos, por exemplo, na Convenção de Bruxelas de 1968, protegem o consumidor em the dando a faculdade de iniciar a demanda contratual no tribunal de seu domicilio ${ }^{23}$. Esta faculdade não pode ser excluída por uma cláusula "Internet", que atribuiria a jurisdição da sede da empresa que fornece a metcadoria ou serviço por este meio ${ }^{24}$.

A mesma questão é posta quanto à lei aplicável a estes contratos. As leis imperativas do Estado no qual o consumidor tem seu domicílio ${ }^{25}$ não podem ser excluídas.

No que concerne aos atos ilícitos cometidos attavés da Internet, a ubiqüidade deste instrumento de comunicação conduz igualmente a perguntas sobre a possível localização dos litígios.

22 Ceja Peter Mankowski, "Das Internet Internet im Internationalen Verttags- und Deliktsrecht", Rabels Zeitschrift, vol. 63 (1999), pp. 203ss.

${ }^{23}$ Veja art. 14, alinea 1, da Convenção de Bruxelas.

24 Veja art. 17, alinea 4, da Convenção de Bruxelas

25 Veja art. 5 da Convençăo de Roma. 


\section{b) Contratos}

Em matéria de contratos, as empresas e seus fornecedores de Internet procuram se proteger através de condiçôes gerais contratuais, que figuram em suas páginas ou sites. $\mathrm{Na}$ Alemanha, um fornecedor de vendas e leilóes de obras de arte inclui em suas cláusulas uma que dispõe o seguinte: "os princípios do direito internacional privado ou dos conflitos de leis ficam excluídos deste contrato"26. Tais cláusulas são nulas, não podendo-se excluir toda a aplicação do direito internacional privado. Estas cláusulas, porém, bem demonstram o receio das empresas de ter de responder demandas judiciais em todas as partes do mundo. A Intemet é caracterizada pelo fato de também os pequenos operadores do comércio eletrônico poderem ter acesso ao mercado. A idéia tradicional de um desequilibrio econômico e social entre a grande empresa e o pequeno consumidor, o fundamento das regras especiais de conflitos de leis e de jurisdição, que proregem a parte mais fraca, não tem plena correspondência no comércio eletrônico.

\section{c) Responsabilidade delitual}

Em matéria delitual, o lugar do delito é o critério decisivo para determinar, seja o foro competente, seja a lei aplicável. A Internet propõe problemas especificos por causa da sua ubiqüidade.

Com relação à responsabilidade da imprensa por violações à personalidade do indivíduo - situação comparável àquela da Internet - a Corte de Justiça das Comunidades Européias multiplicou os lugares do delito como motivos de competência ${ }^{27}$. A "vítima pode intentar contra o editor uma ação de reparação, seja perante a jurisdição do Estado contratante do lugar do estabelecimento do editor da publicação difamatória, competente para reparar integralmente os danos resultantes da difamação, seja perante a jurisdição de cada Estado contratante no qual a publicação seja difundida ou onde a vítima pretenda ter sofrido um atentado à sua repuração, competentes para conhecer somente os danos causados no Estado da jurisdição escolhida"2z.

Entretanto, é preciso notar que somente o foro do editor é competente para conhecer da totalidade dos danos. O que resulta, portanto, é a ubiqüidade dos foros dos delitos,

26 Leilôes da Yahoo/Alemanha: "Anwendbares Recht. Diese Geschäftsbedigungen wie auch die sonstigen Beziehungen zwischen den Nutzer und Yahoo! unterliegen dem deutschen Recht; kollisionsrechtliche Grundsäzze sind ausgeschlossen."

${ }^{27}$ Decisâo de 7 de maxço de 1995, C 68/93, Fiona Shevil c. Presse Alliance, Recueil, 1997, I, p. 417, pp. 450 ss., p. 465.

28 N.da T. : No original: "La victime peut intenter contre l'éditeur une action en réparation soit devant les iurisdictions de l'Etat contactant du lieu d'établissement de l'éditeur de la publication diffamatoire, compétentes pour réparet l'integralité des dommages xésultant de la diffamation, soit devant les jurisdictions de chaque Etat contractant dans lequel la publication a été diffusée et où la victime prétend avoir subi une atteinte à sa réputation, compétentes pour connaitre des seuls dommages causée dans l'Etat de la jurisdiction saisie." 
solução que servirá também para as publicações na Internet. Cada local onde se encontre o computador pelo qual o usuário pode tomar conhecimento da publicação deve ser considerado como local do delito. Se seguirmos esta linha da jurisprudência e da doutrina européias, cada Tribunal terá competência para conhecer os litígios relativos à Intemet.

A jurisprudência americana elaborou certas restrições a este respeito. Tomemos o exemplo de uma decisão tecente de uma Corte de Apelação Federa ${ }^{29}$. Os fatos exam os seguintes: o proprietário de um clube de jazz, The Blue Note, em New York citou num Tribunal daquele estado a propósito de uma ação de proibição do uso do nome Blue Note, contra o proprietário de um cabaré em Columbia, no Mississipi. A ação se fundava, inter alia, na violação das regras de concorrência. A parte acionada havia colocado o nome The Blue Note na Internet, em uma publicidade que podia ser vista em New York. A questão que se punha era se os tribunais de New York eram competentes para conhecer a causa. Os juízes julgaram improcedente a demanda. $O$ simples fato de que a parte adversa, domiciliada em outro estado, utilize o nome The Blue Note, numa publicidade que pode ser vista em New York, não é suficiente para fundamentar a competência dos Tribunais de New York.

As decisões dos juízes europeus demonstram um claro contraste com a jurisprudência americana,

Tomemos o exemplo de um julgamento recente de um Tribunal de Munique, relativo ao litígio entre uma empresa alemã e uma holandesa sobre o uso de uma marca na Internet ${ }^{30}$. O juiz fundou a competência dos Tribunais alemães segundo o critério do lugar do delito que, para a Internet, se encontra em cada lugar onde o site da marca registrada pode ser visualizada por um usuário ${ }^{31}$. Era uma coisa normal que o juiz alemão aplicasse sua própria lei..

\section{d) Crítica}

As soluções do direito europeu, em minha opinião, não são satisfatórias. Em matéria de contratos, as regras tradicionais da proteção do consumidor são demasiadamente amplas. Basta um "clique" para que o consumidor possa se valer dos seus próprios tribunais. De ourra parte, o critério clássico, do lugar de execução de um contrato não é apropriado, se os contratos são realizados on line $e^{32}$.

2y Bensusan Restaurant Corporation v. King, 126 F3d 25 (2nd cir. 1997).

30 LG Munique,I, 21 de setembro de 1999, Recueil der Internationalen Wirtschaft, 2000,pp. 466ss. Tratavase de una medida provisória. Sobre o domain name como 'marca de fato', veja A. Palazzolo, "Il domain name- La nuova girisprudenza civile cotmmentata", 2000,If, pp. 167 ss., p. 176.

${ }^{31}$ Veja LG Munique,I, 21 de setembro de 1999, Recueil der Internationalen Wirtschaft, 2000, p. 466: "Nach ständiger Rechstprechung des angegangenen Gericht ist Ort der unerlaubten Handiung bei Kennzeichnrechtsverletzung durch das Internet Internet jeder Ort, an welchem die Internet InternetDomain bestimmungsgemäss abgerufen wetden kann.".

${ }^{32}$ Conferência de Haía de direito international privado, "Table ronde de Genève sur le commerce électronique et le droit international privé!", Rev. crit. dr. int. pr., 1999, p. 875. 
No que concerne os delitos, poder-se-ia justificar a ubiqüidade da competencia pela proteção das vítimas. Mas os acusados também merecem ser considerados: as ações sem fundamento podem perturbar seus negócios e suas vidas.

Voltarei a estes problemas na segunda parte da conferência.

\section{A liberdade: as obras de arte pertencentes à herança comum da humanidade.}

Abordemos agora a terceira característica das tendências atuais do direito internacional privado: a influência da nova liberdade do comércio. Tomemos como exemplo uma matéria muito sensível para o interesse público, o comércio internacional das obras de arte ${ }^{33}$.

Uma grande decisão da Corte européia de Direitos Humanos (Cout européenne des Droits de lhomme), de 5 de janeiro de 2000 - Beyler v. Itália - concernente ao conflito entre os interesses do Estado em salvaguardar o patrimônio cultural e a liberdade do comércio internacional. Um comerciante suíço havia adquirido, na Itália, uma obra de vân Gogh intitulada O Jardineiro, realizada em Saint Rémy-de-Provence em 1889. Essa pintura fora registrada na Itália como bem, que apresentava um interesse histórico e artístico, fato que determinava um direito à preempção por parte do Estado iraliano. Este direito foi exercido alguns anos após a venda.

A Corte decidiu que o comportamento das autoridades italianas violava o artigo 1 do Protocolo ${ }^{\circ} 1 \mathrm{da}$ Convenção curopéia de Direitos Humanos, segundo a qual "toda pessoa fisica e jurídica tem o direito ao respeito dos seus bens" 34 . Por um lado, a Corte admitiu "o caráter legítimo da ação de um Estado que acolhe de modo lícito em seu território obras de arte pertencentes ao patrimônio cultural de todas as nações e que vise privilegiar a solução mais apta a garante uma grande acessibilidade em beneficio do público, no interesse geral da cultura universal"35.

Por outro lado, a Corte assinalou que "os poderes públicos devem reagir em tempo átil, de modo correto e com a maior coerência"36.

O que se destaca, inicialmente, é o fato da Itália reclamar uma obra de van Gogh como parte do patrimônio culrural italiano. No que concerne o direito

${ }_{33}$ Veja P. Lagarde, "Commerce et protection des biens culturels en droit international privé", Journée de la societé de législation comparée 1986, Paris, pp. 423ss. K. Siehr, "International Art Trade and the l.aw", Recueil des cours, tomo 243 (1993), PP, 9ss; G. Carducci, La restituition des biens culturels et des objets d'art volée ou illicitement exportés, Paris, 1997.

${ }_{34}$ A corte fez reserva da questão sobre uma 'satisfaction équitable' de acordo com o Art. 41 da Convenção. O requerente hava reclamado dans materiais e morais, p. 32 , n. 132.

${ }^{35} \mathrm{~N}$. da T. No original: "le caractère légitime de l'action d'un Etat qui accueille d'une façon licite sur son territorire des oeuvres appartenant au patrimoine cuiturel de toutes les nations et qui vise à privilégier la solution la plus apte à garantir une large accessibilité au bénéfice du plublic, dans l'intérêt général de la culture universelle."

${ }^{36}$ N.da T.: no original: "les pouvoirs publics sont tenus de réagir en temps utile, de façon correcte et avec la plus grande cohérence." 
internacional privado, a decisão é muito interessante. A Corte aplicou, para determinar a proptiedade do requerente, a lei italiana como lei da 'situação' da obra de arte. Para aor aplicação do artigo 1 do protocolo, portanto, bastava um "interesse patrimonial" como bem protegido. Desta maneira, a tegra clássica da lex rei sitae cede aos direitos humanos. De uma parte é um primeiro passo na direção da liberalização do comércio de obras de arte. De outra parte, o interesse público da comunidade nacional ou internacional e os direitos do indivíduo parecem inconciliáveis. Não se pode imaginar apresentar um recurso perante a Corte de Estrasburgo cada vez que uma pessoa deseje exportar uma obra de arte de um pás a outro. É preciso encontrat outras soluções para garantir um equilíbrio entre estes interesses divergentes.

A questão que se põe é saber se a autonomia da vontade pode representar um papel para este fim.

\section{SEGUNDA PARTE - PROPOSTAS E SUGESTÕES}

Na presente parte da conferência volto aos temas da primeira parte, avençando propostas e sugestões para soluções adequadas ao novo milênio. De movo geral, na minha opinião, é preciso proteger a pessoa humana mais por um reforço de sua autonomia do que mediante leis imperativas que se impõem sem levar em consideração as necessidades do indivíduo.

\section{O divórcio: a autonomia da vontade dos cônjuges}

Se retomamos o tema do divórcio internacional, ternos que levar em conta o faro que o direito internacional privado não passa de sombra do direiro substantivo-essencial. O direito europer, como vimos, deveria fundar um sistema de conflitos de leis sobre o reconkecimento das decisões judiciárias. Sabemos que a outra parte do planeta conhece o divórcio consensual registrado por um oficial do estado civil. Pode-se mencionar o Japão, a Coréia, a Tailândia e a China. Entre outros, o sistema judiciário islâmico e no sistema religjoso do Talmude ${ }^{37}$, o divórcio se baseia num ato jurídico privado ${ }^{38}$. Da mesma forma há tendências, na Europa, para admitir o divórcio por consentimento mútuo. A Suíça introduziu este tipo de divórcio, com uma lei recente, deixando ao processo de mediação as negociações relativa aos termos do divórcio, limitando-se a função do juiz a pronunciar a dissolução do casamento. Le divorce en douceur, para citar o título de um livro francês ${ }^{39}$, é a solução do futuro.

No que concerne o direito internacional privado, o direito nacional dos países europeus é mais liberal do que a Convenção européia. O Tribunal supremo da Espanha, por exemplo,

\footnotetext{
${ }^{37}$ Ver Christoph. Herfahrt, Die Scheidung nach jüdischen Recht im internationalen Zivilverfahrensrecht, Heidelberg, 2000.

${ }^{38}$ Paras Diwan e Peeyushi Diwan, Private Internationa! Law - Indian and English, $4^{n}$ ed., New Delhi, 1998, Pp. 280-281.

39) Christine e Daniel Richard, Le divorce en doucer, Paris, 1997
} 
reconheceu recentemente um divórcio japonês por mútuo consentimento ${ }^{49}$. Pode-se citar exemplos semelhantes em outros países.

$\mathrm{Na}$ minha opinião, o direito internacional privado deveria seguir esta tendência, dando mais autonomia de vontade aos cônjuges para escolher a lei aplicável ao seu divórcio ${ }^{41}$. Além disso, o direito internacional privado não deveria impor um procedimentosso judiciário se a lei à qual os esposos estão culturalmente ligados não o prevê. Uma lei alemã de 1986 proibiu, no interior do país, toda forma de divórcio diversa da pronunciada pelo juiz naciona ${ }^{42}$. Trata-se de uma solução que restringe de maneira desrazoávelirascível a autonomia dos cônjuges estrangeiros.

A autonomia de escolha da lei aplicável ao divórcio já foi aceita por diversas legislações ${ }^{43}$. A falta de tal escolha não se poderia pensar na aplicação da lei do último domicilio conjugal. O divórcio por ato privado deveria ser incluído em todas as hipóteses no sistema de conflitos de leis

\section{A Internet e o juiz virtual internacional}

Vimos que o atual estado do direito internacional privado, sobretudo na Europa, favorece a ubiqüidade de foros para os litígios relativos aos negócios provenientes da Internet, uma solução que não parece apropriada à manutenção de um justo equilibrio entre as partes. Mais uma vez, a autonomia da vontade das partes seria una solução que permitiria a salvaguarda da certeza do direito. As partes podem escolher o foro competente e a lei aplicável, se ambos são profissionais ${ }^{44}$.

Se uma das partes é um consumidor, permito-me avençar duas propostas. A primeita trata de uma restrição da jurisdiçãocompetência judiciária ao domicilio do usuário. Poderíamos adorar uma solução elaborada no âmbito do Mercosul e introduzir um foro do autor, se este efetuou sua prestação, vale dizer, o pagamento do preço ${ }^{45}$. O artigo 7, lerra $c$ do Protocolo de

40 Supremo Tribunal, 18 de maio de 1999, Aranzadi, Repertório de Jurisprudência, 1999, $\mathrm{n}^{\circ} 3167$. Ver J. Carrascosa González, "Divorcios extranjeros sin intervención judicial: Prácrica del Tribunal supremo", Estatuto personal y mulciculturalidad de la familia, (A. L. Calvo Caravaca e ). L. Itiarte Ángel, dir. publ.), Madrid, 2000, pp. 39 ss.

${ }^{4 l}$ Ver J. Carrascosa González, Matrimonio y elección de ley - Escudio de Derecho internacional privado, Grenade, 2000, p. 186.

"22 Ver o artigo 17, parágrafo $2^{\circ}$, da Lei de Introdução ao BGB alemão; ver também G. Kegel, "Scheidung von Ausländern im Inland durch Rechtsgeschäft", IPRax, 1983, pp. 22 ss.

43 Ver, para o direito alemão, os artigos 17 , parágrafo $1^{\circ}$, e 14 , parágrafo $2^{\circ}$, da Lei de Introdução ao $B G B$; a autonomia é limitada a certas situações.

${ }^{44}$ Conferência de Haya de Direito internacional privado, "Table redonde de Genève sur le commerce électronique et le droit international privée", Rev, crit. dr. int. pr., 1999, pp. 873 ss, p.875. Ver também Gabrielle Kaufmann-Kohler, "Internet: mondialisation de la communication - mondialisation de la résolution des liviges", em K. Boele-Woelki e C. Kessedjian (dit. publ.), Internet, Deventer, 1998, pp. 89 ss., pp. 122 ss.

45 Ver Jürgen Samtleben, "Das Internationate Prozess- und Privatrecht des Mercosur - Ein Uberblick", Rabels Zeitschrift, 63 (1999), pp.1 ss. 
Buenos Aires (1994) prevê a jurisdição-competência judiciária dos tribunais do Estado do domicílio ou a sede da parte demandante, se esta comprove haver efetuado a prestação devida. É uma solução nova ${ }^{46}$ que leva em conta o fato de que se o demandante cumpriu suas obrigações, merece um foro dentro do seu próprio país. É certo que no Mercosul esta regra não se aplica aos litígios entre os consumidores ${ }^{47}$. Mas poder-se-ia pensar num tribunal do foro do demandante para as causas resultante dos negócios da Internet.

A segunda solução refere-se à nova figura de um juiz virtual internacional competente pata os litígios provenientes dos negócios da Internet. Tál juiz corresponderia bem ao justo equilíbrio entre as partes. O usuário da Internet poderia recorrer a este juiz através do seu computador. É uma solução aventada pelas empresas para prevenir as propostas das autoridades comunitátias européias que prevêem una extensão do foro do consumidor aos negócios da Internet ${ }^{48}$.

Um juiz virtual para os negócios da Internet se assemelha a um rribunal atbitral competente de acordo com as cláusulas compromissórias estipuladas pelas partes. Na minha opinião, tal juiz resolveria o problema da ubiqüidade da internetlnterner. As partes permanecem on line; Obter-se-ia uma "mundialização dos litígios" ${ }^{49}$ sem dar preferência a um juiz "territorial", que seria seja o do usuário seja o da empresa.

A pessoa humana seria protegida pela sua autonomia de recorrer a um tribunal acessivel pelos meios que a Internet oferece para a realização dos negócios.

Pode-se ir mais longe: a lex informatica tornar-se-ia talvez a lei aplicável a tais litígios ${ }^{50}$.Ela se constitui de regras transnacionais de comportamento contidas num código de conduta dos usuários da Inremet $t^{51}$. Sem dúvida, convém que este código seja ainda elaborado $o^{52}$.

\section{O salvo-conduto internacional das obras de arte}

Passemos agora ao terceiro problema, o do comércio de obras de arte. Vimos que existe um conflito entre os interesses do Estado para regular o comércio das obras de arte

46 Jürgen Samtleben, "Ein Gerichtsstandsabkommen für den Südamerikanischen Gemeinsamen Markt (Mercosur), IPRax, 1995, pp. 129 ss. e p.131.

47 Artigo $2^{\circ}$, parágrafo $6^{\circ}$, do Protocolo de Buenos Aires (1994).

48 Ver também as proposiçoes da Eurocommerce e das Eurochanbres, "Der elektronische Marktplatz soll harmonisiert werden", Frankfurter Allgemeine Zeitung, 27 de junho de 2000, p.25.

49 Kaufmann-Kohler, Kaufmann-Kohler, Internet, p. 89ss.

58 Ver St. Hobe, p. 280.

si Ver, por exemplo, Le code de conduite d'Eurocommerce (2000). Ver também J. Delbrück, "Von der Staatenordnung überdie internationale institutionelle Kooperation zur supraterritorial or global governance: Wandel des zwischenstaatichen Völkerrechts zut Rechtsordnung des Menschen und der Völker?", Christiana Albertina, 47 (1998), pp. 5 ss., pp. 13-14.

52 Ver A. Mefford, "Lex informatica: Foundations of Law on the Internet", Indiana Journal of Global Legal Studies, 5 (1997), pp. 211 ss. No que concerne o procedimento extrajudicial, ver, para a União Européia, a recomendação da Comissão, de 30 de matço de 1998, sobte os principios aplicáveis aos órgãos responsáveis pela resoluçäo extrajudicial dos litígios de consumo, JOCE, $\mathrm{n}^{\circ} \mathrm{L} 115 / 31$ de 17 de abril de 1998. Ëstes princípios devem ser levados em consideração para os "litígios da Internet". 
para salvaguardar o patrimônio nacional e o interesse do individuo em participar de um comércio livre sem fronreiras. Este conflito parece insolúvel, mas a questão é saber se a responsabilidade de tais problemas poderia igualmente residir na revalorização da autonomia das partes, mesmo nesta matéria delicada.

O direiro do comércio das obras de arte é uma matéria que está se transformando profundamente. Uma idéia nova é a do salvo-conduto para as obras de arte $e^{53}$. A França o introduziu pela lei de 8 de agosto de 1994, a seguinte regra:

"Os bens culturais emprestados por uma potência estrangeira, uma coletividade pública e uma instituição cultural estrangeira, destinadas ao público na França estão livres de arresto pelo período do seu empréstimo ao Estado francês pelo próprio Estado ou por qualquer pessoa jurídica. Uma decisão conjunta do Ministro da Cultura e do Ministro das Relações Exteriores fixa, para cada exposição, a lista dos bens culturais, determina a duração do empréstimo e designa as organizações da exposição".

A Alemanha seguiu o exemplo francês com a lei de 15 de outubro de $1998^{54}$. Esta lei introduziu um procedimento processo de obtenção de uma decisão da autoridade competente, decisão que garante a restiruição ao emprestador do bem cultural. Este aro público tem por efeito proibir, por parte de terceiros, a reivindicação, por parte de terceiros, dos direitos relativos aos bens emprestados.

Na verdade, é sempre o Estado que concede o salvo-conduto internacional de uma obra de arte. Além disso, as leis mencionadas constituem uma resposta a casos especiais de obras emprestadas pelos museus dos países da Europa Oriental, reivindicadas por pessoas privadas expropriadas $s^{55}$. Finalmente, ficamos no campo reduzido dos empréstimos para os quais esta solução foi elaborada ${ }^{56}$. Por outro lado, o ato de garantia do salvo-conduto constitui o primeiro passo na diseção de um acordo entre as autoridade estatais e as pessoas interessadas no que se refere à migração rransfronteiriça de obras de arte.

Pode-se esperar que ral exemplo influenciará também o direito relarivo ao mercado de arte.

A auronomia da vontade das partes, fundamento clássico da determinação da lei aplicável aos contratos internacionais, encontrou um grande apoio numa decisão recente da Corte européia dos direitos do homen de 5 de janeiro de 2000 , que acentuou a necessidade de um justo equilifbrio "entre as exigências do interesse getal da comunidade e os imperativos de salvaguarda dos direitos fundamentais do indivíduo" ${ }^{\text {"57 }}$. Esta nova tendência é confirmada

5.3 Ver E. Jayme e A. Geckler, "Internationale Kunstausstellungen: Freies Geleit für Leingaben", IPRax, 2000, pp. 156-157.

${ }_{54}$ "Gesetz zur Umsetzung van Richtinien der Europäischen Gemeinschaften über die Rückgabe von unrechtmässig aus dem Hoheitsgebiet eines Mitgliedstaats verbrachten Kulturgütern und zur Anderung des gesetzes zum Schutz deutschen Kulturgutes gegen Abwanderung" de 15 de outubro de 1998 , Bundesgesetzblatt, 1998, I, pp.3162 ss.

\$5 Ver E. Jayme, "La revendication de la propriété d'oeuvres d'art - Quelques affaires en Europe", conferência proferida em Genève (a ser publicada).

${ }^{56}$ Ver N. Palmer, Art Loans, Kluwer, 1997.

${ }^{37}$ Deter-se Beleyer c. Italie, n.14. 
pela lei austríaca recénte relativa à proteção do patrimônio cultural. No contexto da proteção dos jardins históricos, a lei faz com que a aplicação das regras de direito público dependa da autorização dos proprietários particulares ${ }^{58}$. Os direitos fundamentais dos indivíduos são respeitados. Entre tais direitos figura também a autonomia da pessoa humana de celebrar contraros e de dererminar ela mesma as leis aplicáveis a estes conrratos.

A idéia do salvo-conduto das obras de arte, obtida por acordos entre as autoridades estarais e as pessoas privadas, favoreceria, além do mais, uma certa "desnacionalização" de bens culturais que, num mundo global, pertencem à toda a humanidade. Na minha opinião, os interesses das nações, como os de salvaguatdar os bens culturais ditos "nacionais" estão perdendo sua importância vis-à-vis a dos direitos culturais dos indivíduos que reclamam uma participação à herança cultural mundial"

\section{CONCLUSÕES}

\section{A proteção da pessoa humana por meio da autonomia da vontade das partes}

Há, em direito internacional privado, para a proteção da pessoa humana face à globalização, dois enfoques jutídicos. Os Estados podem, para a aplicação de tal proteção, suspender as regras imperativas de aplicação imediata qualquer que seja a lei normalmente aplicável ao contrato. Este enfoque ainda domina os atos legislativos relativos aos conflitos de leis em matéria de contratos individuais de trabalho. Pode-se mencionar leis recentes de países membros da União Européia que concernem a transferência temporária de trabalhadores ${ }^{60}$. O futuro direito do trabalho necessitará de uma flexibilidade mais ampla. Impor, como lois de police, as disposições do Estado onde o trabalho se realiza, a meu ver é retrógrado.

Para os conflitos de jurisdição uma tal solução conduziria a foros da parte demandante dita "fraca" e à proibição das convenções atributivas de jurisdição.

O outro enfoque seria o de teforçar a autonomia da vontade das partes que poderiam escolher a lei aplicável e o foro competente para seus litígios, solução pela à qual eu desejaria optar.

58 "Bundesgesetz, mit welchem das Bundesgesetz betreffend Beschränkungen in den Verfügung über Gegenstände von geschichtlicher, künstierischer oder kultureller Bedeutung (DenkmalschutzgesetzDMSG) geânndert wird", Bundesgesetzblatt für die Republik Österreich, parte I, 19 de agosto de 1999 , par. 3 (5). Na mesma direção exprime-se a decisão da Corte Constitucional Alemã relativa à proteção do patrimônio cultural, sentença de 2 de março de 1999, BVerfGE, n ${ }^{\circ} 100$, Pp. 226 ss., p. 246.

${ }^{59}$ Ver J. Blake, "On Defining the Cultural Heritage", International and Comparative Law Quarterly, 49 (2000), pp, 61 ss., pp. 81 ss.

60 Ver, para o direito alemão, W. Däubler, "Neue Akzente im Arbeitskollisionsrecht", Recht der Internationalen Wirtschaft, 2000 , pp. 255 ss, pp. $257+259$. 
Eu percebo sinais para uma tendência que o professor von Overbeck caracterizou como "irresistivel extensão da autonomia em direito internacional privado" ". As ligaçōes objetivas, como o lugar do delito ${ }^{62}$, são vistas dentro da ótica da vontade das partes que está sendo acolhida mesmo nos sistemas jurídicos que a rejeitam ${ }^{63}$. Além disso, pode-se mencionar a escolha tácita escondida da lei aplicável para a eleição de foros alternativos ${ }^{64}$. Finalmente, a autonomia é realizada em direito africano onde a opção do estatuto é considerada como uma solução de direito adquirido.

O segundo enfoque, quer dizer, a dada autonomia, não deixa a pessoa humana desamparada. É mais "Hilfe zur Selbsthilfe" 65 , ajuda a se auto-ajudar pela garantia de uma informação apropriada que encontramos nos atos comunitátios mais recentes em matéria de proteção de consumidores ${ }^{66}$. Velocidade, ubiqüidade, liberdade, estas características da globalização não constituem uma ameaça para uma pessoa informada.

\section{Mensagem para a ciência: comparação global das regras de conflitos}

Assim chegamos à finalidade da nossa Academia. Se falamos de informação chegamos também à educação. A mensagem para o ensino da ciência do direito internacional ptivado é a informação sobre os conflitos de leis e jurisdiçôes com base numa comparação mundial de

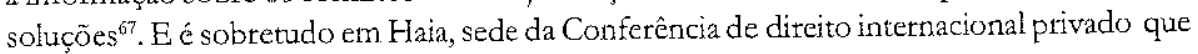
é preciso guardar a vocação de elaborar e de sonhar soluções giobais.

st A. von Overbeck, "L'irrésistible extension de l'autonomie en droit international privé", Nouveaux itinéraites en droit. Hommage à Frrançois Rigaux, Bruxelles, 1993, pp. 619 ss. Ver também Javier. Carrascosa González, Matrimonio y elección de ley - Estudio de Derecho internacional privado, Grenade, 2000; Y. Nishitani, Mancini und die Parteiautonomie im Internationalen Privatrecht, Heidelberg, 2000 , pp. 277 ss. Para o retorno ao valor da autonomia individual, ver A Somma, Autonomia privata e struttura del consenso contrattuale - Aspetti stotico-comparativi di una vicenda concettuale, Milan, 2000 , pp. 427 ss. Ver também R. Sacco, "La diversità nel diritto (a proposito dei problemi di unificazione)", Rivista di diritto civile, 2000, 1, pp. 15 ss., p. 30 ("ampliando ao máximo o âmbito da autonomia contratual e negocial"?.

${ }^{62}$ Ver R. Freitag e St: Leible, "Das Bestimmungsrecht des Art. 40 Abs. 1 EGBGB im Gefüge der Parteiautonomie im Internationalen Deliksrecht", Zeitschrift für die vergleichende Rechtswissenschaft, vol. $99(2000)$, pp. 101 ss.

6.3 Ver Nadia de Araújo, Contratos Internacionais: Autonomia da Vontade, Mercosul e Convenções internacionais, $2^{\circ}$ ed., São Paulo, 2000.

${ }^{64}$ Ver J. Carrascosa González, Matrimonio y elección de ley - Estudio de Derecho internacioná privado, Grenade, 2000, pp. 194 ss.

w Sandra Kind, Die Grenzen des Verbraucherschutzes durch Information- aufgezeigt am Teilzeitwohntechtegesetz, Berlin, 1998, p. 539.

${ }^{66}$ Ver também J. B. Harrison e M-J. Jefferson, "(S)ome (A)ccurate (I)nformations is (B)etter than (N)o (1)nformation (A)t (A) 1 : Arguments Against an Exception to the learned Intermediary Doctrine based on Direct-to-Consumer Advertising, Oregon Law Review, 78 (1999), pp. 605 ss.

67 Ver M. Reimann, "A New Restatement - for the International Age", Indiana Law Journal, vol. 75 (2000), Pp. 575 ss., pp. 583 ss. 